\title{
Participatory design methods when working in remote locations: The case of Red Puna in north west Argentina
}

Article

Accepted Version

Murray, C., Doak, J., McNeil, K. and Oms, P. (2020)

Participatory design methods when working in remote locations: The case of Red Puna in north west Argentina. The Design Journal, 23 (2). pp. 1-24. ISSN 1460-6925 doi: https://doi.org/10.1080/14606925.2020.1726663 Available at https://centaur.reading.ac.uk/87020/

It is advisable to refer to the publisher's version if you intend to cite from the work. See Guidance on citing.

To link to this article DOI: http://dx.doi.org/10.1080/14606925.2020.1726663

Publisher: Taylor \& Francis

All outputs in CentAUR are protected by Intellectual Property Rights law, including copyright law. Copyright and IPR is retained by the creators or other copyright holders. Terms and conditions for use of this material are defined in the End User Agreement.

www.reading.ac.uk/centaur 
Central Archive at the University of Reading

Reading's research outputs online 


\title{
The Design Journal (in press)
}

Participatory Design Methods When Working in Remote Locations: The Case of Red Puna in North West Argentina

Murray, C.; Doak, J.; McNeil, K.; Oms,P.

Corresponding author Dr Claudia Murray c.b.murray@reading.ac.uk

\begin{abstract}
Cross-disciplinary initiatives are raising demand for participatory design methods that can be applied at different scales, from urban settlement planning to individual buildings. However, there is a gap in the literature in terms of participatory tools and processes for international design teams operating at the local level in geographically remote regions. This paper presents the findings from a series of design workshops carried out by an international and interdisciplinary team working with small communities of Andean farmers in north-west Argentina. The team used a blend of participatory tools including walkabouts, collective model-making and a bespoke method for collective drawing. The team also gathered contextual data via individual and community surveys. The study shows the importance of context (i.e social, economic, political and policy) in the decision making process of participants, and reflects on communication problems when working in geographically dispersed locations.
\end{abstract}

Keywords: participatory tools, collaborative design; community engagement; decision-making processes

\section{Introduction}

The internationalisation process of architectural and design consultancies have increased the cultural exposure of design professionals vis-à-vis the use of participatory design processes that intend to capture the multitude of views and behaviours of today's culturally diverse societies (Imrie and Raco, 2003). In the UK for example, a long history of community engagement practices in planning - a history 
that stretches back half century according to Rydin (1999)- has achieved prominence by the emphasis placed on neighbourhood planning via the Localism Act (2011). A similar attitude towards public engagement has emerged in other parts of the world, and most particularly in developing countries, many of which are building more bottomup approaches in relation to their development trajectories (Wates, 2000).

Parallel to this, academic research into participatory design techniques has also developed since the 1970s (Cross, 1971; Sanoff, 2000; Luck, 2003; Simonsen and Robertson, 2012). There is also an extensive academic literature that examines the issues that these methodologies face. Problems range from failure to engage all sectors of society, with particular issues of favouritism and clientelism (Bénit-Gbaffou, 2011), through the failure to engage with minority groups (Sarmiento, 2013), to the costs, user-friendliness and effectiveness of virtual representations and other technologies for design visualisation (Al-Kodmany, 1999 and 2001; Loebekke, 2009). There are additional problems related to the scale of projects and possibilities of inclusion (Sanoff, 2000; Purcell, 2006). In terms of the participation process, there are also debates about timing; whether participation should occur at the early stage of the design, throughout the process or at the end (Klausen and Sweeting, 2005). More generally, questions have been raised about the methods and effectiveness of participatory design in situations where obvious imbalances in political and economic power exist amongst the range of groups and interests involved (Bentley 1998 and Carmona 2014a).

However, none of this literature looks at the challenges facing international design teams acting at the local level in geographically remote regions. A number of questions arise from this: How do international design teams operate at local level? What participatory design tools can they use? Do factors like local culture, needs and strengths play a part in the decision-making process of collaborative design? If so, how? How do they handle the implications of the power relations inherent to the design process of which they are a part? What happens when international design teams work remotely, i.e. in a different geographical region to where the community lives? To address these questions this paper presents the findings from a series of design workshops carried out during 2013 and 2014 by an international and interdisciplinary team working with small communities of Andean farmers in north-west Argentina. The 
workshops sought to develop a vision for community buildings that were suitable for the particular needs and activities of the farmers, and to take that forward with collaborative drawing of the actual buildings.

\section{Theoretical Framework}

Matthew Carmona (2014a and b) provides a framework for evaluating processes and outcomes of urban design exercises which is useful for the purpose of this study. Carmona points to three key dimensions involved in place-making:

- historical and policy 'contexts';

- place-shaping 'processes'; and

- 'power relationships'.

With regard to 'contexts' Carmona draws specific attention to the historical processes of place in which past experience and practice tends to influence and shape contemporary attitudes and actions in an inherited urban fabric (including landownership, buildings and layout). The other contextual component is the pervasive influence of existing, but often dynamic, governmental polity and policies which structure the opportunities available within particular areas and developments. The second dimension, 'processes' of urban design, is discussed by the author in relation to four phases of the overall development process and includes:

- design,

- development,

- space in use and

- subsequent place management.

Significantly, and relevant to this paper, Carmona argues that the 'design' phase involves a number of steps that each help to shape place. They include:

- establishing a vision,

- making trade-offs,

- innovating - or not; and 
- creating value and shaping constraints.

Establishing a vision tends to be both a creative and iterative process in which stakeholders, working within local contexts, produce ideas and indicative outcomes. Trade-offs are then made as the initial concept and principles are taken forward within an environment in which physical, economic and environmental constraints impinge on the vision. Steps toward innovation (or not) are often made to deal with these constraints and the importance of creating value (economic, environmental or social) will permeate this evolving translation of initial vision into built form.

In the analysis of Red Puna's case study, the paper follows Carmona's place making dimensions of context, processes and power relations. However, and given that the 'processes' dimension only reached designs stage, the evaluation disregards the other phases of 'development'; 'space in use' and 'place management'. Figure 1 shows the resulting analytical framework underpinning this study.

Figure 1: Analytical framework

Analytical Framework (based on Carmona, 2014 a and b) for the study of Red Puna design workshops

\begin{tabular}{l} 
Historical and policy \\
contexts \\
Place-shaping 'processes' \\
Design Phase: \\
Establishing a Vision \\
Making Trade-offs \\
Innovating (or not) \\
Creating Value \\
Shaping Constrains \\
\hline Power relationships
\end{tabular}

Pre field-work data collection (survey and contextual background study)

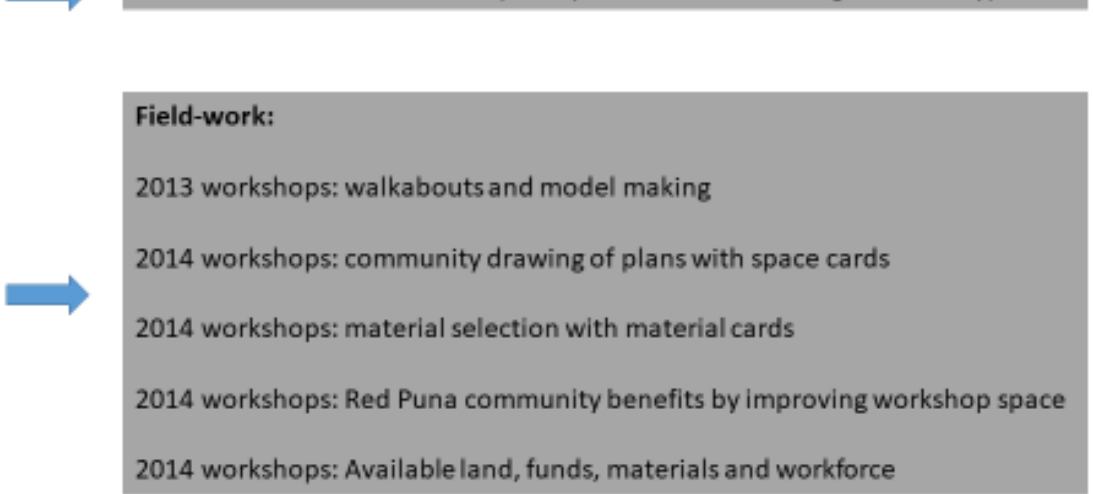

Post field-work analysis of design workshop and communication dynamics

The remaining structure of the paper is in four sections. First, an explanation of the approach and methods including the collaborative tools employed. Second a brief description of the workshops' participants, considering the historical and policy contexts (Carmona's first dimension of place making). The third part is the main body 
of the paper and presents the analysis of the design stage, including establishing a vision, subsequent trade-offs and value creation during the collaborative workshops. The fourth part considers Carmona's final dimension of power relations emerging during the workshops. Given the international nature of the work, reflections on communications when working in geographically dispersed locations are also presented in this section. The paper ends with the conclusions on the effectiveness and limitations of participatory design when working in remote locations and reflects on the cultural and contextual forces operating in the collaborative workshops.

\section{Approach and Methods}

The participatory design workshops in North West Argentina were led by a team of researchers from the University of Reading, Coventry University and Architecture for Humanity, and with support from students from the Argentine University of Enterprise, (UADE) and University College London. The team worked with seven different communities, all members of the Red Puna Co-operative, a network of farmers spread around the Andean mountains of Jujuy Province (Figure 2). Given the size of the area $\left(53,219 \mathrm{~km}^{2}\right)$ and the geographical barriers that the Andes impose on road communication, Red Puna is organised into five smaller units, each named after the sub-region they serve: North, West, South, Centre and Quebrada. The Centre and Quebrada sub-regions form the geographical core and is where community representatives from across the organisation meet. The network has a social worker appointed by the government that has been the research team's main point of contact throughout the project. The first introduction was possible via an academic colleague from the University of Buenos Aires, who put Red Puna in touch with the University of Reading's team in 2012.

The initial request presented by Red Puna was whether the team could offer guidance on how to maximise/expand workshop space for the production and commercialisation of their craft. The workshops are community-owned buildings used for numerous activities including meetings, festivities and capacity-building workshops. The buildings are therefore an important part of the community's life but most are in a state of disrepair, have poor sanitation and, most importantly, lack decent overnight accommodation; something that brings problems of exclusion to the cooperative as 
some farmers live in remote places and cannot make the journey to these locations in just one day.

Figure 2: Geographical location of Red Puna villages

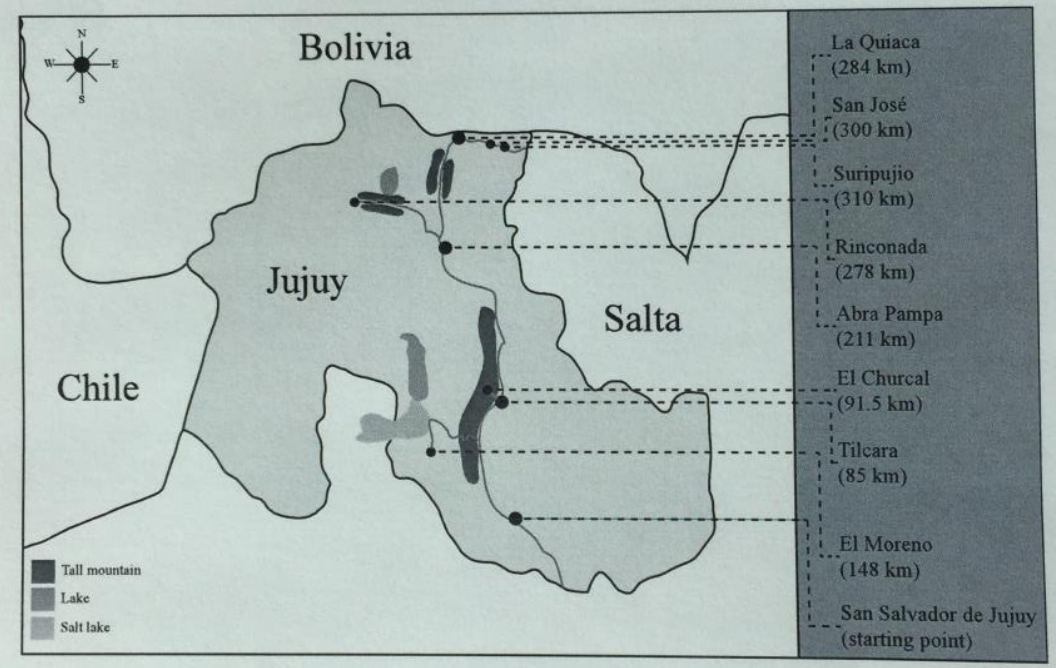

Prior to visiting the region, the team developed a questionnaire survey, with the aim of gathering contextual information and building an understanding of individuals' lives, needs and strengths (see Appendix 1 for questionnaire template). The survey was sent electronically to the social worker who distributed it amongst all communities for completion. Communities responding to the survey included Rinconada (Red Puna 
West), San Jose, La Quiaca and Suripujio (Red Puna North), Abra Pampa and El Churcal (Red Puna Centre and Quebrada), and El Moreno (Red Puna South), thus representing all regions covered by the cooperative.

Participatory workshops with the communities during the first visit (August 2013) concentrated on model making to develop a vision for the buildings. From September 2013 to October 2014, the team worked in London developing a suitable tool for the second round of workshops, which aimed at refining and drawing the community buildings. In October/November 2014, the team carried out the second round of workshops that focused on drawing the buildings' layouts, facades and finishes. Finally, the team produced detailed architectural plans drawn-up according to design specifications established during the workshops. These were handed over to the community representatives in 2015. Figure 3 illustrates the staged approach to this community engagement process.

Figure 3: Project stages 
PROJECT STAGES:

STAGE 1: DATA COLLECTION FOR CONTEXTUAL UNDERSTANDING

Questionnaire survey completed individually by Red Puna

members and desk-based background research on politics and

policies.

STAGE 2: DESIGN VISION WORKSHOPS

Use of engagement tools to develop an initial concept for the buildings. This phase also included additional data collection in graphic and audio formats.

STAGE 3: DEVELOPMENT OF PARTICIPATORY TOOL

Team based in London developing a collaborative drawing tool that reflected data collected in Stage 1 and 2.

\section{STAGE 4: COLLECTIVE DRAWING WORKSHOPS}

Filed work with the communities using the tool developed in Stage 3.

STAGE 5: HANDING OVER OF FINAL PLANS TO RED PUNA

Preparation of final drawings based on sketches developed in Stage 4.

In total, the team conducted thirteen workshops with Red Puna, collecting data in visual and audio format (see Appendix 3 for full list of semi-structured interviews). This data was added and crossed-referenced with the survey results mentioned above. When relevant, originals were translated from Spanishi into English and data was coded and inputted into Excel files for statistical analysis.

\section{Participatory Tools Employed}

The team used walkabouts and workshops as the two main collaborative tools. Walkabouts took place in the mornings, allowing the international team to familiarise 
themselves with each place and survey the building sites whilst engaging the community, encouraging them to tell their personal and collective stories. This also provided an opportunity to learn about Red Puna's craft-making processes, information that later fed into the programmatic elements required for the future buildings. Participatory workshops ran for the rest of the day, taking the lunchtime break as an opportunity for a more informal engagement including preparing and eating meals, thus sharing activities that are familiar to all groups regardless of cultural background. Design workshops were of two formats: collective model-making and the collective drawing of building plans. The next section explains the rationale behind the selection of each method as well as the development of the participatory drawing tool.

\section{Collective model-making during 2013 round of workshops:}

In the creative process, model-making or prototyping is a technique often used after initial sketches are developed (Lawson, 2006). However, the team wanted to encourage Red Puna participation and brainstorming but faced the question of how to directly connect the community's ideas with spatial thinking and drawing, given that workshop attendees had little technical or sketching abilities. The advantage, however, was the high level of craft-making expertise, therefore making conceptual modelling a relatively easier tool for them to use and communicate ideas. Prototyping has also been used in other contexts with positive results (Innella and Rogers, 2017). As the authors suggest, 'quick-and-dirty' prototyping is an effective way of communication in inter-cultural situations where the 'language' of making something together, as well as the roughness and speed of the method of building with what is available, helps to bring down barriers in terms of language and design skill capacity.

The team therefore selected collective model-making as the most appropriate initial tool to create a vision and easily communicate in a 3-dimensional way. Prior to the workshop sessions, the team briefed each community, encouraging them to bring discarded materials (cardboard boxes, empty containers, etc.) to build conceptual models which constituted the first expression of the community's vision for their places (first step in Carmona's design phase - see Figure 1). Workshop utensils (glue, cutters, scissors, etc.), were provided by the team. The brief for workshop participants at this stage was to reflect on their needs and have free-range to express a vision without budgetary or regulatory constraints. The aim here was to get an initial blue-sky concept that could be later refined during the follow-up drawing workshops. 
Collective drawing of building plans during 2014 workshops:

After the 2013 model-making workshops, the team worked in London developing a participatory user-friendly drawing tool which was portable, adaptable and avoided use of sophisticated technical equipment. Equally, the tool had to enable a refinement of the blue-sky models made by Red Puna, so that users could begin a process of decision-making and refining the design concept (i.e make trade-offs, innovate and create value according to Carmona's designs steps presented in Figure 1). As an essential activity in developing the tool, the team used data collected in the community walkabouts and building surveys carried out in 2013, in particular data related to craft production which covered the whole process from looking after the llamas in the fields to wool and meat production in the community workshops for commercialisation.

With the data collected, the team developed a series of cards that were of two types: spaces and materials. The 'space' cards graphically represented Red Puna's llamabased production activities in a two-dimensional format that clearly indicated the space requirements for such activity by sketching a person in the card. For example, for weaving activities a card was designed representing the space required by one weaver and a loom, and if more weavers were required then more cards could be added until the available space was filled. The cards were not to scale but had a clear indication of measurements needed for each step of craft production, including machinery and space for circulation. Other communal activities, such as meat processing for food, were represented in one single card which had all the activities (from stripping the meat to cooking and packing) represented in the same card.

Figure 4: Space cards 


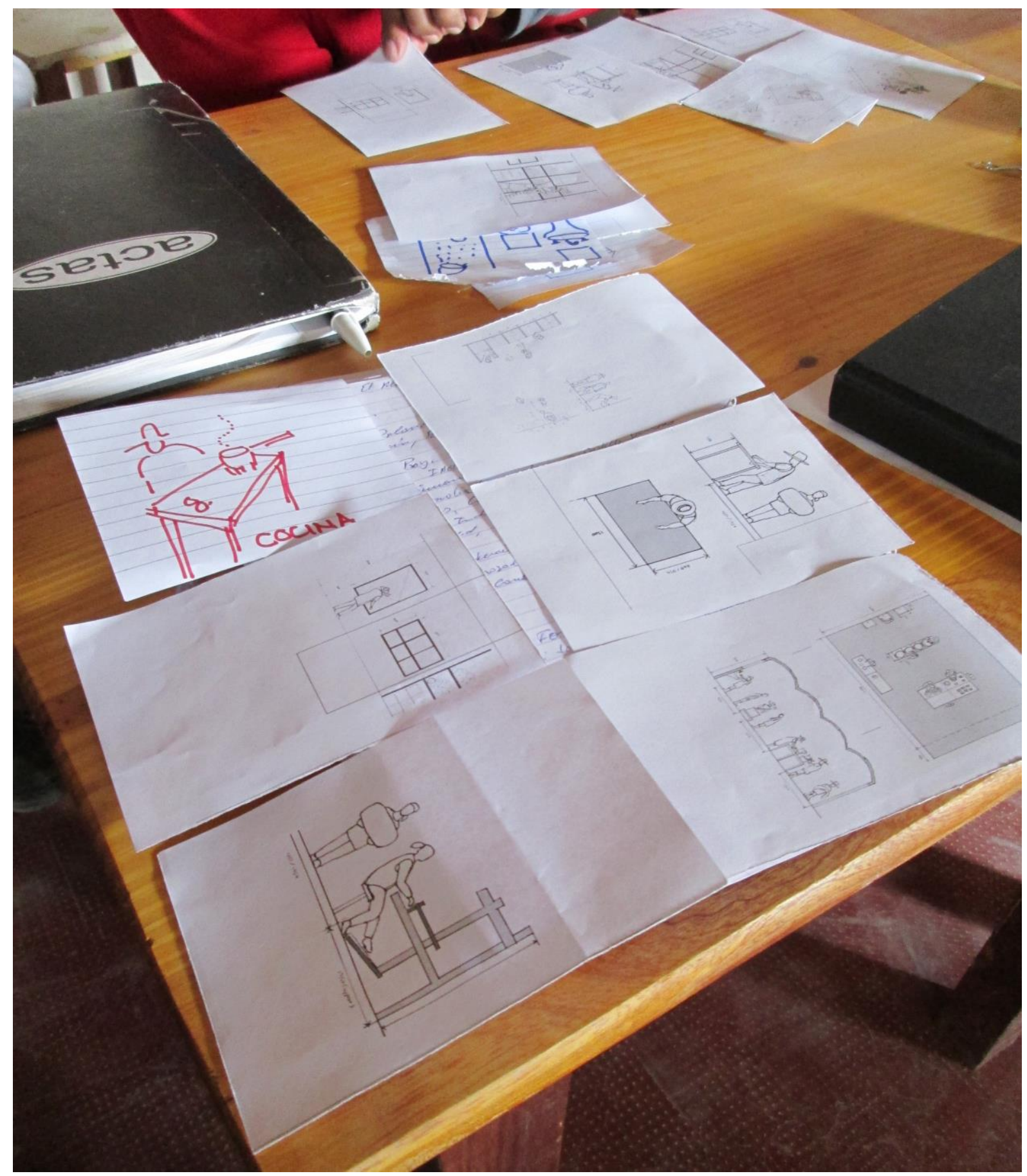

The other set of cards represented 'materials' (Figure 5) and these were designed inline with local architectural tradition, using the textures and colours identified by the communities as culturally important during the 2013 walkabouts. In Carmona's design stages, the cards aimed at stimulating innovation by encouraging Red Puna to rekindle the use of traditional mud-bricks which have lately been replaced by concrete blocks. Red Puna members used both sets of cards to help them refine the original blue-sky designs made during the first workshops. There was a year difference between the 
first stage of the design and the second, but all communities had kept the original models for reference during the second round of workshops.

Figure 5: Materials cards

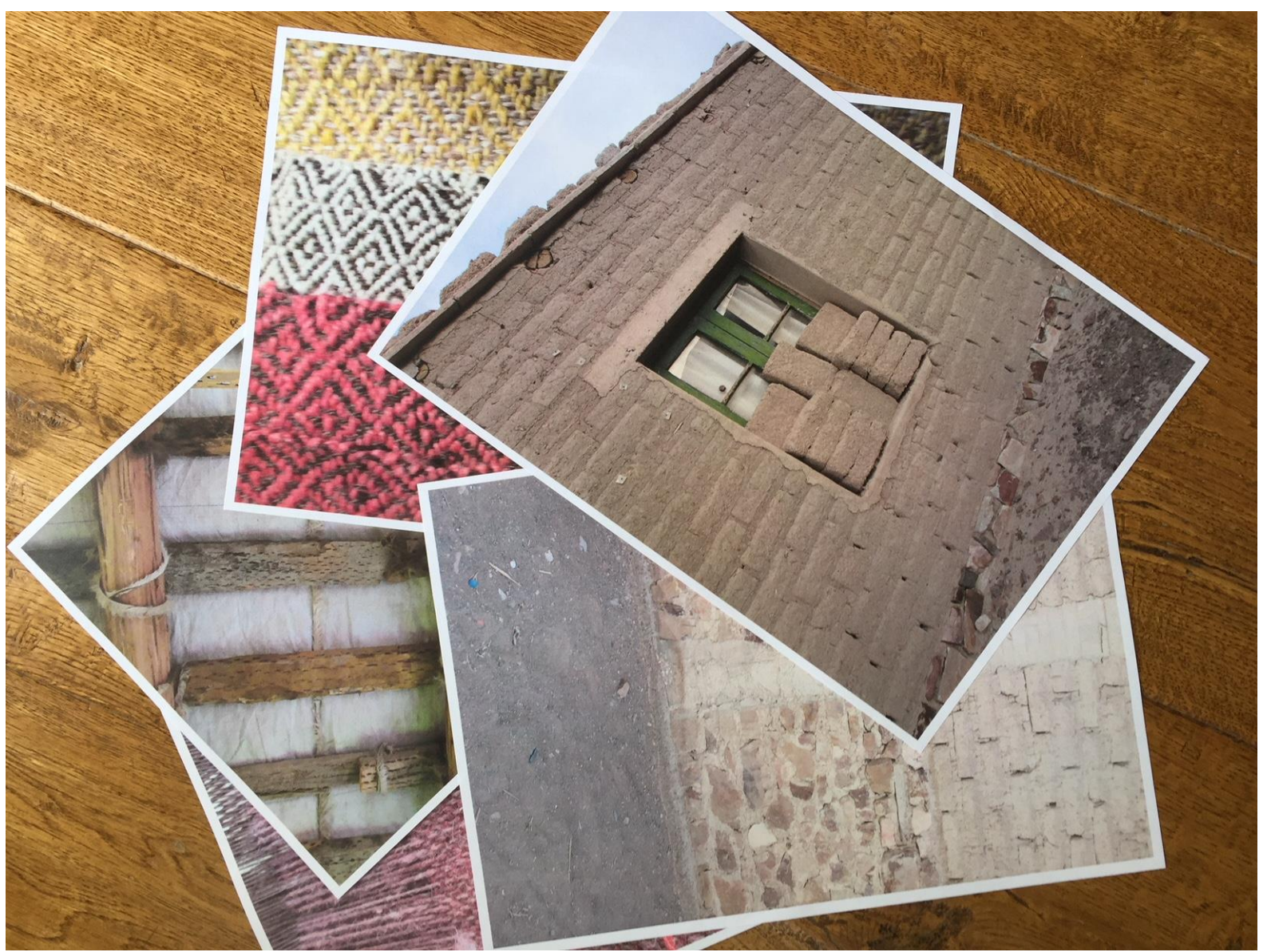

\section{Historical and policy context of workshops' participants:}

Culture, land struggle and politics

Red Puna members belong to the Coya ethnic group of indigenous people who have been working the land and trading in the region for over 10,000 years. The survival of the local communities, their culture and llama-based economy is a core objective of Red Puna. In 2003, the region was awarded World Heritage status based on its cultural significance. This was a major achievement for the community that now hoped to attract an international trade for the sale of their craft (Interview 7). However, the community did not consider the negative externalities that arrived with achieving worldwide recognition, such as the increase in tourism, which brought demand for holiday homes and the development of new hotels and resorts, which have had a direct impact on land availability and prices (Interview 6). 
Furthermore, there are two salt lakes in the area (Salinas Grandes). These are rich in lithium, a valuable mineral for the production of batteries to power computers, mobile devices and electric cars. During the Kirtchner administration (2003-2015) and in light of the higher global demand for lithium, the Argentine government sold exploitation rights to international mining companies (Brent, 2012). As some authors claim (Dulitzky et al, 2009), the mining companies are forcing the Coya off their agricultural land, as well as causing severe pollution in the area. These conflicts prompted an official visit from the United Nations (UN) in 2007 and a subsequent written reprimand to the Argentine government, urging them to protect the natural environment and its native population (Anaya, 2012).

In 2007 Red Puna, with some support from international aid organisations (e.g. Heifer International and the Inter-American Foundation), secured some training provided by textile designers from the University of Buenos Aires. The training involved methods to improve craft production (quality and consistency of goods) in order to sell in bulk to other retailers in Buenos Aires. Notwithstanding, international aid was aimed at capacity-building to improve craft production while infrastructure building was dependant on national/local government resources which were (and still are) scarce. Consequently, Red Puna workshop's spaces often have poor sanitation, are overcrowded (partly due to the success of the cooperative in improving craft quality), unhealthy and lack overnight accommodation for community members travelling from remote parts of the region. The workshops carried out by the team highlighted these issues by identifying Red Puna's parameters of a well-designed environment for communal activities, which facilitate increasing economic productivity. From an academic perspective, the workshops provided an opportunity to 'test' and evaluate participatory design approaches facilitated by an international team working in remote rural locations. It can be argued that, for Red Puna, the collaboration was an attempt to generate further international attention to add weight to the business case for government funding for infrastructure building.

\section{Analysis of workshop results:}

Establishing a vision 
Figure 6: Collective model-making

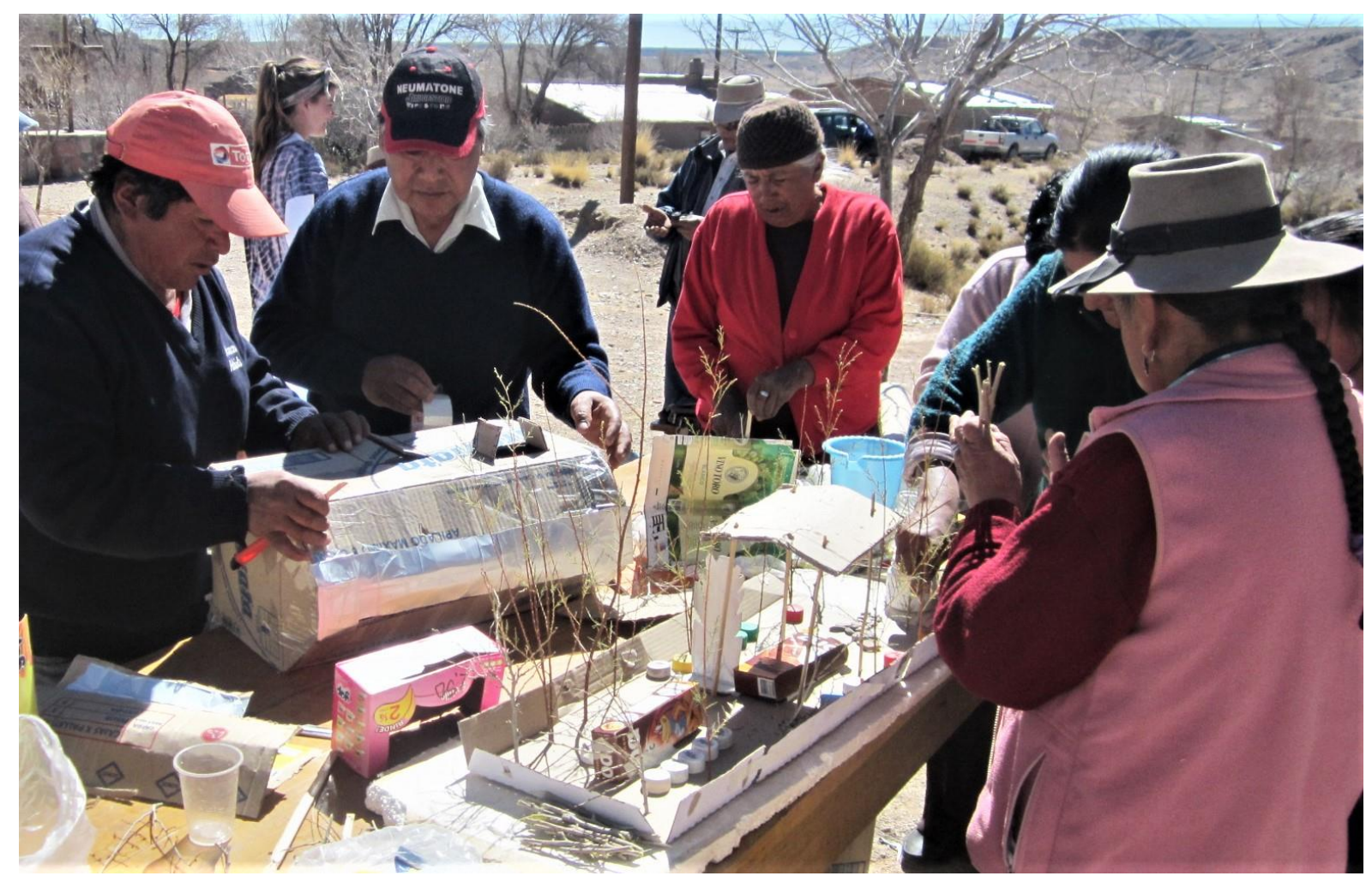

The team used collective model-making as a way to develop a vision and an initial concept with Red Puna (Figure 6). Amongst the different methods employed by architects during this part of the design process is the use of a particular building type as a reference (Rowe, 1987). This, as the author suggests, can be due to functional or technological preferences, i.e typologies that are easy to build with local resources or that have proven to maximise usage of space for a particular function. It was interesting to see that all Red Puna communities preferred a rectangular shed as a building type, even when they had the free choice during the blue-sky thinking of the collective model-making phase. The rectangular shed is not only a local vernacular and a recognisable form in the area (Figure 7), but is also technologically possible for Red Puna. As it transpired from the survey, most members built their own houses following this traditional typology (Figure 8). Therefore, it is very likely that the familiarity of the rectangular shed and its technical feasibility played an important part in Red Puna's initial choice. The size of the building plots also plays a part, as most villages' plots are rectangular, following the traditional colonial grid system. However, some communities such as Abra Pampa with large square-shape plots were still happy to stick to the rectangular shed, while others like Rinconada, with a square sloping 
site, proposed the refilling and levelling of the plot, therefore easing the construction of a rectangular shed on one side of the plot.

Figure 7: The vernacular rectangular shed

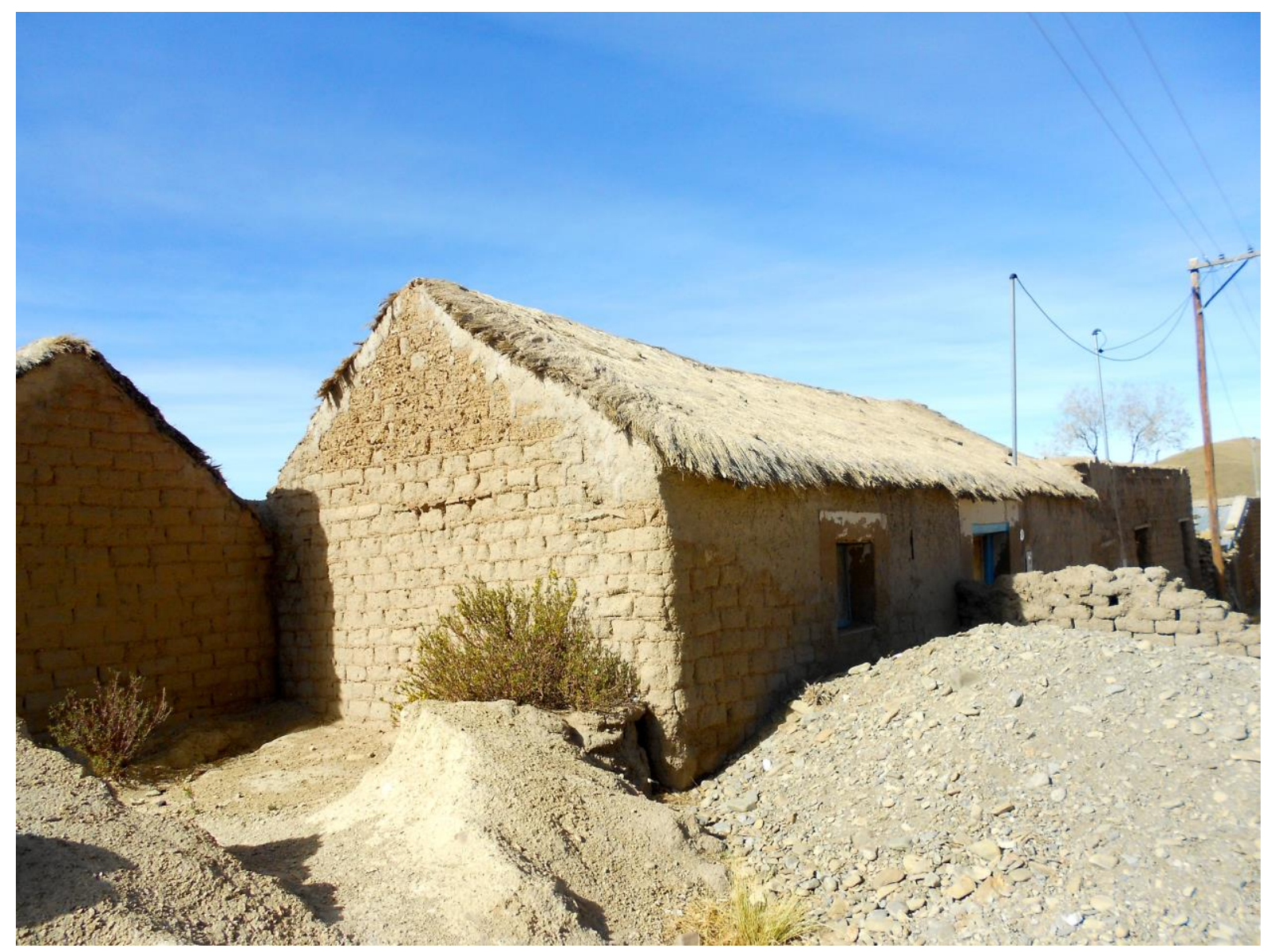

Figure 8: Houses built by Red Puna 


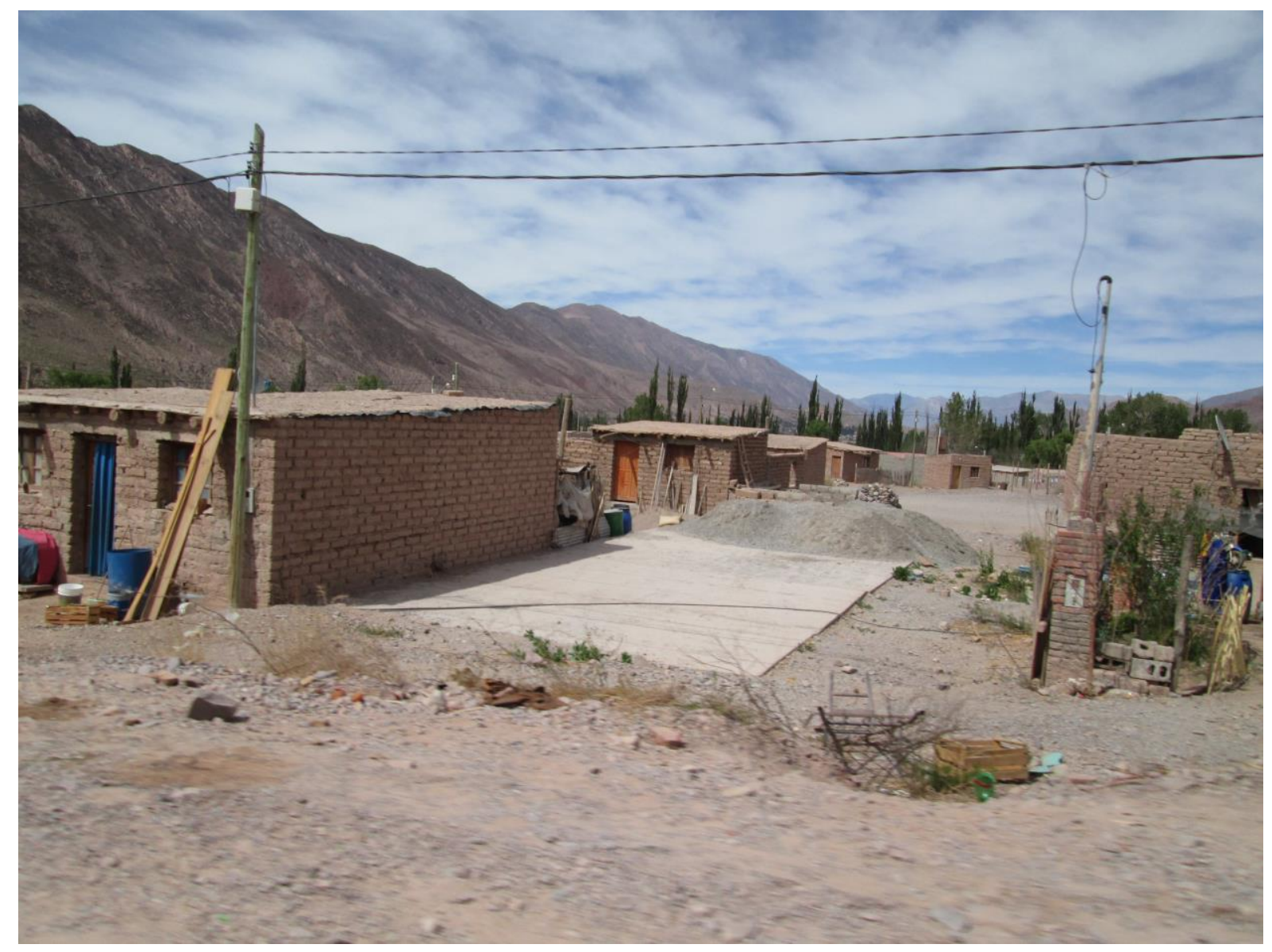

\section{Making Trade-offs}

The a priori use of the rectangular shed conditioned the subsequent decision making process during the drawing workshops in 2014. This was the stage when Red Puna used the cards designed by the team in London. It must be highlighted that the strategy for the workshops was to 'hand over the pencil.' Over time, the team step back from the table, becoming observers and ensuring that pencils and other drawing implements were made available. The international team acted as facilitators, therefore, following the conceptual models they had, the first drawing step for all communities was to draw a rectangular outline of the building. Then they proceeded to discuss the location and function of the rooms, distributing the cards within the layout and arranging their orientation. When running out of cards, the team drew additional ones but had no other further intervention in the process.

All communities made a clear division of functions inside the buildings according to the programmatic elements of: workshop, commercial outlet, community kitchens and private rooms for overnight accommodation. Maintaining the rectangular shed 
typology throughout the design process and sometimes linking two such buildings to make an $L$ shape, particularly when they realised the final building length surpassed the available plot length. After a series of iterations and trade-offs, the results fed into the final drawing of building layout plans as seen in Figures 9 and 10.

Figure 9: El Moreno

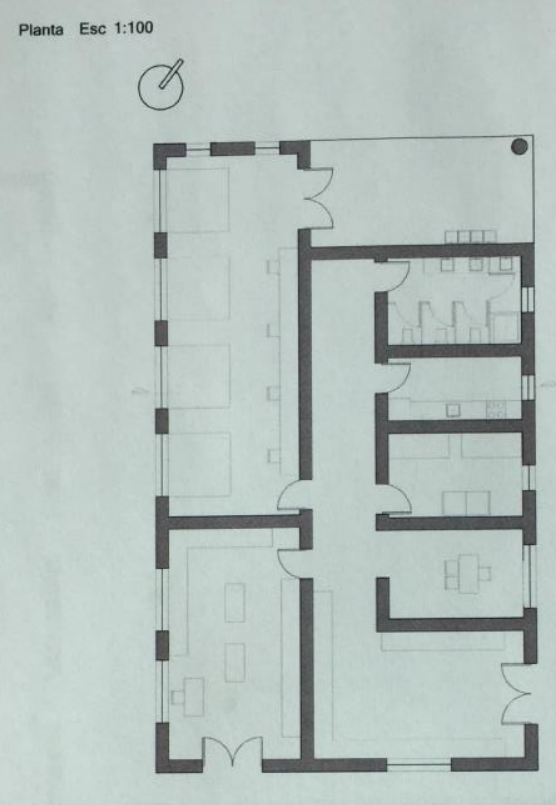

Corte Esc 1:100

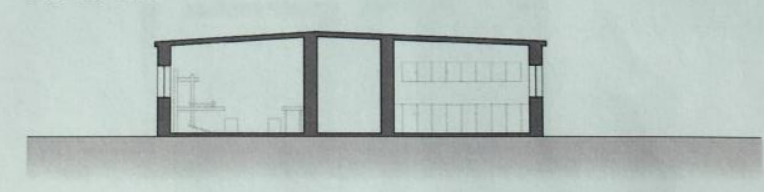

Vista Norte Esc 1:100

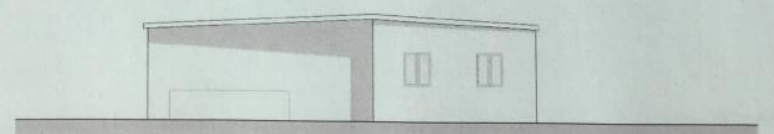


Figure 10: Suripujio

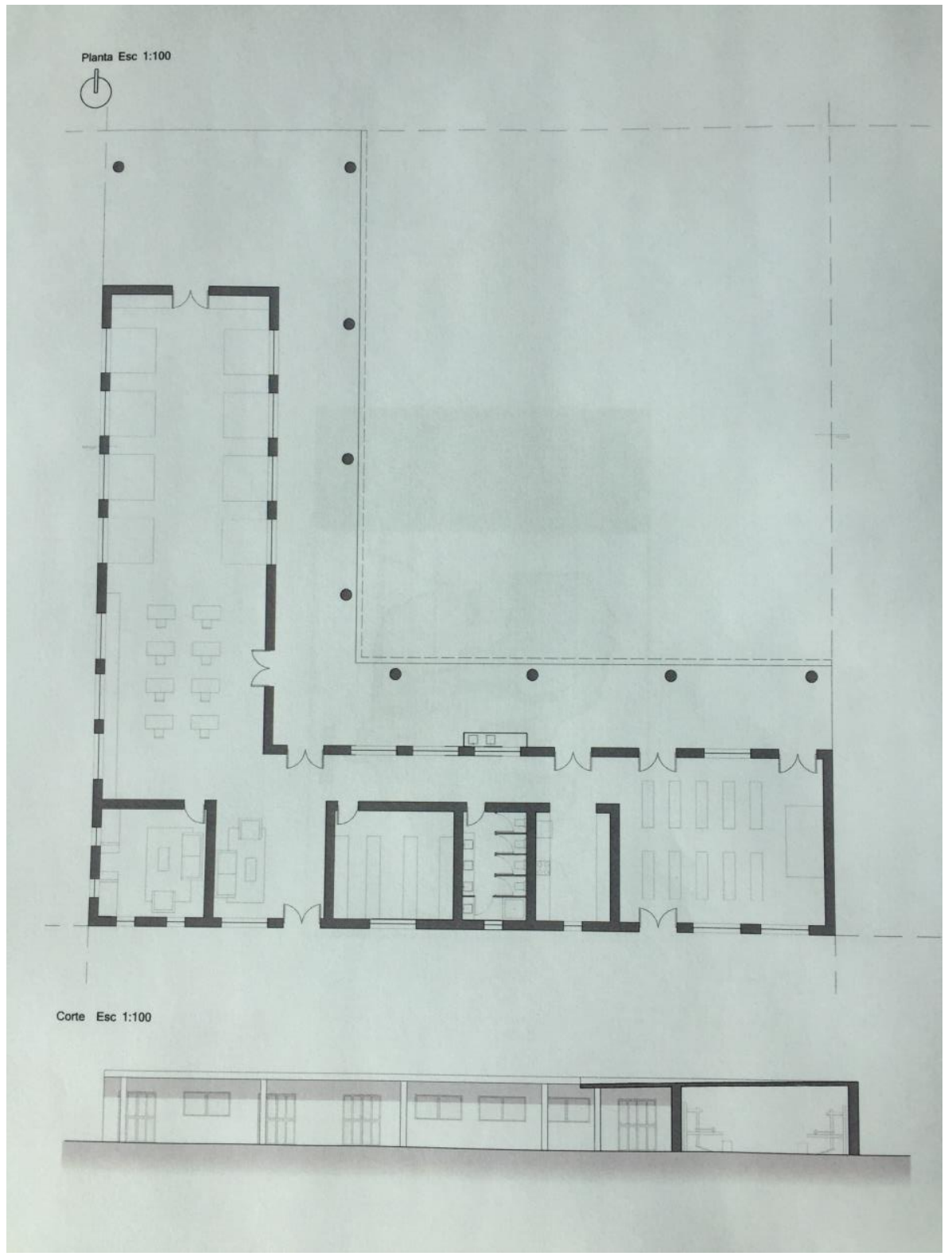

Innovation (or not)

The team then presented the materials cards to select colours and textures and consider buildings' finishes. Prior survey results showed that the communities valued their architectural heritage but only if this had a financial reward, for example if the buildings attracted more tourist and therefore financial income. Otherwise, the traditional adobe brick and reeds roofs are, according to Red Puna, materials that need constant maintenance. It was therefore no surprise that the selected building material was concrete blocks for its speed of construction and low maintenance in comparison with adobe. Discussions on technological aspects of the buildings soon 
unfolded -mostly led by men, proposing incremental building alternatives, particularly when spatial needs became obvious as building layouts were taking shape and Red Puna members were able to measure the overall size of the constructions.

The team later translated these layouts into architectural drawings, thereby completing a relatively reflexive, open and collaborative design process.

\section{Creating value and shaping constrains:}

The process of creating value by Red Puna members during the workshops can partly be explained by their conformity with theoretical prescriptions of the perception of 'good architecture' and 'good design' (Rowe, 1987). During the survey, the team collected information on the communities' understanding of a good place in order to avoid the imposition of the team's own notions of the term and to understand design choices made by Red Puna (see Appendix 1, part $\mathrm{H}$ question 8 of the questionnaire). Answers were grouped according to four predominant and recurring themes (Table 1).

Table 1: Description of a good place to live and work according to Red Puna members

\begin{tabular}{|l|r|}
\hline \multicolumn{2}{|l|}{$\begin{array}{l}\text { Table 1: Description of a good place to live and work } \\
\text { according to Red Puna members }\end{array}$} \\
\hline Places should: & $37 \%$ \\
\hline Provide basic services & $6 \%$ \\
\hline Keep local culture alive & $15 \%$ \\
\hline Help economic development & $42 \%$ \\
\hline Achieve a better natural and built environment \\
\hline & \\
\hline Total & $100 \%$ \\
\hline
\end{tabular}

The largest group (42\%) considered that a good place to live and work has to offer a better natural and built environment than the one they currently have. Within this group, six respondents imagined a good place to live as 'with more trees', twenty-four mentioned more comfortable and larger built spaces (both communal and individual), 
while two wished for better weather conditions. The second largest group (37\%) stated that a good place was one that had basic public services including water, electricity and transport. One of them pointed out that a good place had to have good flood barriers (respondent 2), hinting at the difficulties some communities face with increasing environmental disasters affecting the region. Others within this group stressed the need to offer education for the young and "a good kitchen and a toilet" (respondent 67). Housing conditions were also mentioned by respondent 27 "better houses and drinkable water." Only one respondent (12) mentioned infrastructure in public spaces, stating that a good place to live, "has public places that are well lit". For some respondents (15\%) a good place is a place where people own the land and are in control of their own resources for survival: "An ideal town is where we are able to live from our own products, for our own consumption and for sale" (respondent 50). This clearly show their concern for the local economy and the land struggle with mining companies mentioned earlier. Only a small minority (6\%) related a good place to live with the local culture.

These understandings of a good place need to be contextualised in relation to the respondents' current living conditions. The survey results show that the average household size is five persons and the average number of bedrooms is two. These rooms are separate from the kitchen and $32 \%$ of them stated that they use these rooms for other purposes, such as storage. $13 \%$ of the respondents lack kitchens and cook outside the house using a wood fire or a hob connected to a gas cylinder. $7 \%$ of all surveyed families have no toilets, while $43 \%$ use latrines that are either located inside the house or in an adjacent shack. In terms of urban infrastructure, the type of drainage system used varies. Some villages have a sewage system (EI Moreno, La Quiaca, Abra Pampa) whilst others have septic tanks (Suripujio, San Jose and Rinconada). El Churcal lacks all basic services, being an informal settlement where the community is in conflict with local authorities over land rights (Interview 3a). Furthermore, the quality of the services in all villages depends on whether families live close to the village centre or not. The research team visited some houses in the outskirts of small towns, usually the preferred location for those that have farm animals in the house, and these had very few facilities (see Figure 11).

Figure 11: House on the edge of St Jose village 


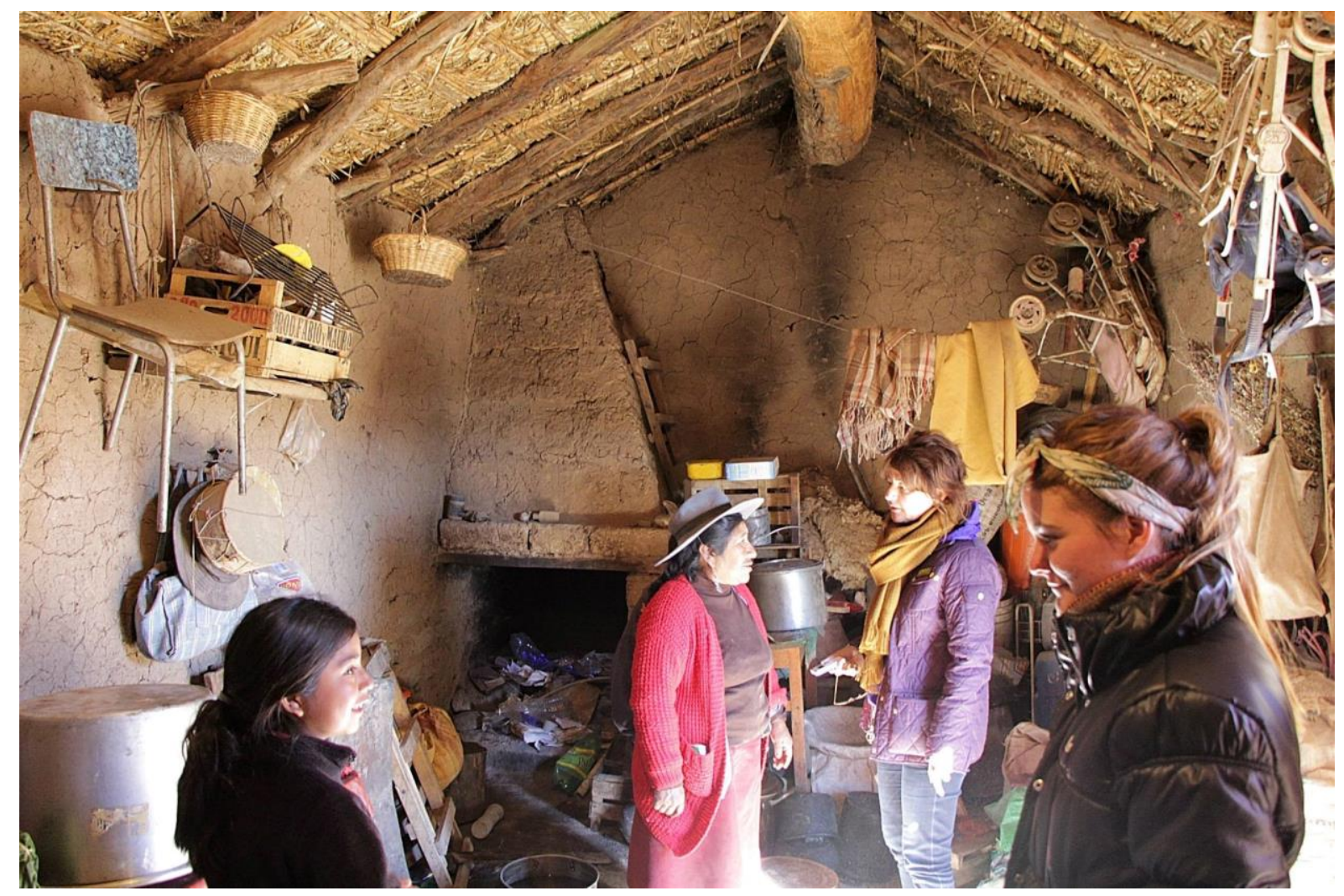

This lack of facilities appears to affect the villagers' confidence and pride, particularly when hosting local religious celebrations: "When we have a local celebration for our Patrona [village patron saint], they come from all other villages and all we have are these toilets [interviewee nods at the public toilets]. They must think we live like animals" (Interview 9, 2014).

In summary, when it comes to defining a good place to live, Red Puna members seem to prioritise the provision of basic services and better quality of the built environment. As a result, the value-creation process in all workshops was heavily influenced by utilitarianism, looking to maximise and improve the familiar rectangular shed, reluctant to innovate and experiment with strengthening the adobe bricks, preferring instead the concrete blocks that need less maintenance in a region where flash floods are causing havoc to their lifestyles and buildings. Construction and labour costs was also a factor influencing their decisions. Red Puna has very little faith in supportive government action. In the survey, only $3 \%$ considered that the government could help to build better buildings in their communities. Instead, Red Puna members have more faith in their own community efforts, with $47 \%$ stating that buildings could be materialised by rallying local resources. The thinking behind this is probably based in the Coya's 
mutual aid system, called minga, which is spread widely amongst Andean cultures (Fernandez-Baca et al, 2010). Minga simply means working as a community, so it is expected that farmers come and help each other during harvesting periods or neighbours provide labour and materials during house building or renovations (Interview 6).

This strong community ethos was a contextual foundation stone for running the participatory workshops, while local land and economic struggles, government neglect and local conceptions of good places, helped the international team understand the community's constraints and value-creation objectives during the design process. In sum, the design phase of the place-shaping dimension was characterised by decisionmaking processes and trade-offs that had a strong utilitarian angle, with technological preference for known building typologies and construction methods that curtailed innovation, built with communal resources via the Minga system as a way to overcome national and regional government funding constraints.

\section{Power relations}

Carmona (2014a, p.30) emphasises that power relationships between the various actors and stakeholders, "sit at the heart of the urban design place-shaping dimension, dictating the flow and function of the process itself, and the nature of its outcomes". On that basis, constant reflective evaluation was required in order to map the power relationships and understand where and how they operated during the workshops.

Sensitivity to both the contextual factors and the nature (opportunities and constraints) of the design processes meant that the international team had to work carefully to build an effective participatory approach. Some clear contextual power forces were at play and also structured the decision-making process of Red Puna, the most obvious ones being the conflicts with the international mining companies and the government over land rights, as well as the element of dependency that the local communities have on the policies and financial resources of regional and, more significantly, central government. However, the Coya (and Red Puna in particular) have not been in the past just passive receivers of political and policy influences; they were also able to mobilise and utilise some political, economic and cultural 'capital' themselves as they 
did when they secured funding from Heifer International and the Inter-American Foundation in 2007. In the context of the design workshops and considering the willingness of Red Puna to participate, it could be argued that the international team itself was 'used' by the cooperative to help legitimise and support their claims for governmental resources....and for their wider campaign for legal rights to land (in order to construct these community buildings). The fact that Red Puna later used the plans produced during the workshops to apply for government funding is a testimony of this. Also proving, notwithstanding, the success of the workshops as the cooperative's sense of ownership of the designs is also clear.

A linked question that also needs addressing is, whose agenda was being constructed and taken forward during this design process? As suggested above, the relationship between the international team and local communities was constrained in many ways, through technical, linguistic and cultural differences. However, a relatively open and trusting relationship was slowly built through face-to-face communication, contextual understanding, community agenda setting and design facilitation using the nontechnical design tools. The 'power' of design modelling (Biddulph 2014) implemented through the use of collaborative model making-tools, allowed the local communities to lead the design process from the initial vision in a user-friendly way, despite the apparent 'imposition' of the workshop structure by the international team.

Of course, Carmona does draw our attention to the fact that power relations are dynamic and likely to change as the design process moves forward into 'development' 'use' and 'management'. An immediate change in the relationship between the Coya and the national government appears to have taken place as the relatively supportive socialist Kirchner administration made way in December 2015 for the new government headed by the distinctly neo-liberal conservative incumbent Mauricio Macri. This is also having knock-on effects with a more open policy towards international mining companies in the region. These contextual shifts in political power are setting new policy and resource 'constraints' but they are likely to be accompanied by similar movements at the micro scale should the building designs constructed during this process be taken forward into construction (using various resources with their own rules and ties attached). However, it could be argued that (at least at the present time) the local communities 'own' their building plans and that they will use these as a 
bargaining tool when negotiating with governmental and other actors sitting around the regional development table.

\section{Challenges When Working in Geographically Dispersed Locations}

The Minga system, as well as Red Puna's experience in dealing with international teams and participating in workshops, made the collaborative design exercise relatively easy. This section now looks at some final considerations in relation to communications, especially when teams work in geographically dispersed locations.

Remote communication with the social worker and community leaders of the Red Puna network was mostly via Skype, WhatsApp and email. This was initiated by the Spanish speaking members of the research team. However, even if the language barrier could have been overcome by having all team members as native speakers, communications in geographically dispersed locations rely heavily on access to good telecommunications and the use of computers or mobile devices. Facilities in each town were limited. The informal settlement of El Churcal was particularly difficult, lacking infrastructure of any kind, including telecommunications. In addition, only one community member in this location had at the time a mobile phone. Thus, due to a misunderstanding about the date of the second visit, the team was unable to complete the second workshop as originally planned. In El Moreno, the community has no internet access and the telephone connection is unreliable, even though some members have mobile phones. Most of the villagers have to take the $140 \mathrm{~km}$ journey to Tilcara in order to check their email, something that some of them do on a monthly basis (Interviews 7 and 8). Places with unreliable mobile phone signal and no internet access, like San Jose and Suripujio, are served by communication 'hotspots' in the larger towns. San Jose is only a $16 \mathrm{~km}$ from the town of La Quiaca but people from Suripujio have to travel along an unsurfaced dirt road for $35 \mathrm{~km}$ to reach it. Red Puna members will do this journey two or three times a week in order to have access to internet and read emails.

Remote communications with Red Puna were therefore sporadic. Community leaders were copied in emails sent to the social worker, however, throughout the 3-year project, the team received only three email responses from Suripujio, two from El Moreno, and one from Abra Pampa and La Quiaca respectively. Communications 
were more frequent with the social worker based in Tilcara, one of the larger town and communication hotspots. Correspondence exchange was mainly to arrange the logistics before field work began and for Red Puna members to feedback minor modifications to building plans after the design workshops had been completed. The poor quality of local telecommunications can be attributed to the main reason for the low levels of e-communication between the team and Red Puna.

Furthermore, email writing demands a moderately good command of language in terms of grammar and spelling. Our survey showed that only $47 \%$ of Red Puna members completed primary education, while only $21 \%$ completed secondary school. One respondent never went to school, while $16 \%$ did not complete primary education (and $15 \%$ did not respond to this question). It is likely that, in addition to the technological barrier, lack of education made e-communication even more problematic. However, one benefit of these technical and educational constraints was that they encouraged the international team to place more emphasis, and extend more effort, on the face-to-face communications involved in the workshops.

\section{Conclusions}

This paper has described and evaluated an example of an international and interdisciplinary design team working in a remote location, and assessed collaborative design tools that can be used to build a culturally sensitive approach to participatory design.

In order to embed the process as closely as possible with the understandings and interests of the native communities, the team approached the design process in carefully orchestrated stages. During the first stage, profiles of each community (and Red Puna as a whole) were built using a questionnaire survey of individual members. This profiling covered the socio-economic character of Red Puna's operation and of individual sub-groups and it assembled an understanding of local conceptions of a good place to live. This was done to establish the design process, as far as possible, in local contexts and concerns from the ground up, and place the community at the heart. The survey work showed that scarcity of natural resources locally and problems over 'legal' access to land rights are having an impact on livelihoods and this in turn 
influences local views about the core features of a 'good place' to live. Notwithstanding these threats, the strength of the minga tradition appears to provide a good base from which local communities are building some resilience to cope with a challenging environment. Based on this tradition, and in contrast to the problems with remote communication, the participatory workshops and field work activities with Red Puna members ran with few difficulties. The structure of the face-to-face engagement process including walkabouts to understand the context, collaborative model-making to create an initial building concept, and collaborative drawing to make trade-offs and create value, proved useful and effective. Walkabouts enabled the team to become familiar with the farming cycles and craft making of all the communities visited, whilst explaining this cycle allowed Red Puna members to see the space-time connections of building design in a very practical way. The use of collaborative model-making reduced inhibitions and gave Red Puna a sense of ownership at a crucial stage of the design process: that of the initial concept. The bespoke drawing tool, the design cards, were easily understood by all attendees to the workshops and the final agreed plans, which included the specification of layouts, colours and materials, show the success of this approach. The fact that in 2015 Red Puna moved ahead with the plans, and applied for funding for the construction of the buildings to the National government, is evidence of their level of ownership of the project, even though the funding was rejected. This success was achieved by:

a) engaging with the communities from the start of the project and continuing their participation throughout;

b) making a determined attempt to understand local understandings of a good place to live and work; and

c) providing the communities with a user-friendly tool to design their own spaces based on their everyday activities.

As suggested, poor access to unreliable telecommunication networks affected the ability to interact effectively with these remote villages when working in the geographically dispersed locations of North West Argentina. Educational attainment appeared to be another obstacle. Both issues, connectivity and education, are partly dependent on wider national policies, as are many of the threats coming from natural resource scarcity and insecurity of land title. The concern remains that if resolutions to these issues are not found soon, the strength of Red Puna's resilience might not be 
maintained in the future. The sustainability (in all senses) of this World Heritage area requires sensitive development at both the local and national/global levels. The global visibility of the region through these types of community engagement has potential to connect Red Puna with communities in other parts of the world who are experiencing similar challenges. The international team can therefore be considered as both facilitators of community ideas and micro agents of long-term social change.

\section{References}

Al-Kodmany, K. (1999). Using visualisation techniques for enhancing public participation in planning and design: Process, implementation, and evaluation. Landscape and Urban Planning, 45(1), 37-45.

Al-Kodmany, K. (2001). Visualization tools and methods for participatory planning and design. Journal of Urban Technology, 8(2), 1-37.

Anaya, J. (2012). Report of the Special Rapporteur on the rights of indigenous peoples. The situation of indigenous peoples in Argentina. Human Rights Council, 21st session. Agenda item 3. Available at: http://unsr.jamesanaya.org/docs/countries/2012report-argentina-a-hrc-21-47-add2_en.pdf [Accessed 03/11/2017]

Bénit-Gbaffou, C. (2011). Up close and personal - How does local democracy help the poor access the state? Stories of accountability and clientelism in Johannesburg. Journal of Asian and African Studies, 46(5), 453-464.

Bentley, I. (1998) Urban Transformations: Power, People and Urban Design, London: Routledge

Biddulph, M. (2014) Drawing and thinking: representing place in the practice of placemaking, Journal of Urban Design, 19(3), pp.278-297.

Brent, Z. (2015). Territorial restructuring and resistance in Argentina, The Journal of Peasant Studies, 42, 3-4, pp. 671-694. 
Carmona, M. (2014a). The place-shaping continuum: a theory of urban design process, Journal of Urban Design, 19(1), pp. 2-36.

Carmona, M. (Ed.) (2014b) Explorations in urban design: An Urban Design Research Primer, London: Routledge

Cross, N. (ed.) (1971). Design Participation: Proceedings of the Design Research Society Manchester: Academy Editions.

Dulitzky, A., Nasr, D., Spangenberg, E., Vail, M., Willett, C., \& Wooten, M. (2009). Abra Pampa: A Community Polluted, A Community Ignored. The Struggle for Environmental and Health Rights in Argentina. Human Rights Clinic. School of Law, University of Texas. Available at: https://law.utexas.edu/wpcontent/uploads/sites/31/2016/02/AbraPampa_Englishversion.pdf [Accessed 03/11/2017]

Fernandez-Baca, E., Montoya, M., Yahum (2010) Innovation for poverty reduction with inclusion in the Andean region, Panorama Andino. Available at https://www.researchgate.net/publication/47328972_INNOVATION_FOR_POVERTY _REDUCTION_WITH_INCLUSION_IN_THE_ANDEAN_REGIONPanorama_Andino _-_Learning_from_case_studies_on_locally_promoted_innovation_experiences [Accessed 3/11/2017]

Imrie, R., and Raco, M. (2003). Urban Renaissance? New Labour, Community and Urban Policy. Bristol: The Polity Press.

Innella, G. and Rodgers, P. Making sense: harnessing communication through prototyping, The Design Journal, 20(1), 1154-1166

Klausen, J., \& Sweeting, D. (2005). Legitimacy and community involvement in local governance. In M. Haus, H. Heinelt, \& M. Stewart (Eds.) Urban Governance and Democracy: Leadership and Community Involvement (pp. 214-233). London: Routledge. 
Lawson, B. (2006) How Designers Think: The Design Process Demystified, London: Routledge.

Loebbecke, C. (2009). Further distributed participative design. Unlocking the walled gardens. Scandinavian Journal of Information Systems, 21(1), 77-106.

Luck, R. (2003). Dialogue in participatory design. Design Studies, 24, 523-535.

Purcell, M. (2006). Urban democracy and the local trap. Urban Studies, 43(11), 19211941.

Sanoff, H. (2000). Community Participation Methods in Design and Planning. Canada: Wiley \& Sons.

Sarmiento, C. (2013) Traversing the border. Community-based planning and transnational migrants. Journal of Planning Education and Research, 33(3), 336-347.

Simonsen, J., and Robertson, T. (eds) (2012). Routledge International Handbook of Participatory Design. London: Routledge.

Rydin, Y. (1999). Public Participation in Planning. In J. B. Cullingworth (Ed.), 50 Years of British Urban and Regional Policy (pp. 184-197). London: Athlone Press.

Wates, N. (2000) The Community Planning Handbook: How people can shape their cities, towns and villages in any part of the world. London: Routledge. 


\section{Appendix 1:}

Red Puna questionnaire (English version)

\section{Part A: Basic statistics}

1- Please provide the name of the cooperative you belong to:

2- Age

3- Marital status

4- Children $\mathrm{y} / \mathrm{n} \quad 5^{-}$- If yes how many?

\section{Part B: Education}

1- Skills/profession

2- Did you attend school? y/n If yes how many years? What level did you achieve?

$3^{-} \quad$ Have you got any training in construction?

4- Have you built your own house?

5- Have you worked in any construction site? If so, provide details of your job there.

\section{Part C: Household}

1- How many people live in your house?

2- How many are working? please provide ages of all working people

3- How many are still studying? please provide age of all students

4- How many infants not yet at school? please provide ages

\section{Part D: House quality}

1- How many rooms are in your house?

2- What are the main materials in your house adobe / concrete blocks or other?

3- Have you got water in the house?

$4^{-}$How many toilets are there in the house?

$5^{-}$How many bedrooms?

\section{Part E: Livelihood}

1- Are you an owner or tenant?

2- Do you have agricultural land?

3- Have you got animal stock?

4- What is the size of your breeding herd?

$5^{-} \quad$ How many off-springs the herd provides each year?

6- How many you keep? how many you sell?

7- Agricultural products (please provide details of type of products you grow and quantities per season)

8- Textile: please provide details of type of product: textile or clothing and quantities of each.

9- Where do you sell these items? Please provide markets/places where you sell

10- Do you mostly sell or trade?

11- If trade what are your needs that you cannot produce?

12- What is the main source of income in your household?

13- Do you need to support your family by any non-agricultural jobs?

14- If so what do you do?

\section{Part F: You and Red Puna}

1- When did you join Red Puna

2- Please specify reasons for joining

3- How does your family benefited from Red Puna, could you provide examples?

4- How do you think the new buildings/infrastructure will benefit the Red?

5- How do you think they will benefit your community?

6- How do you think they will benefit you and your family?

\section{Part G: You and the environment}

1- Have you noticed changes in the local seasons weather?

2- Do you think these changes are due natural changes? (for example climate change)

3- Do you think this changes are due to man-made changes?

4- How are these changes affecting your livelihood? Please provide examples of quantities/percentage change if you have them

5- Where is you nearer source of water?

6- How do you get there?

7- Do you think water availability is sufficient? 


\section{Part H: Architecture for Humanity}

1- Have you heard of this organisation before?

2- How do you think AfH can help Red Puna? And how your community? And you and your family?

3- Have you participated in community discussions before?

$4^{-}$If so how often?

5- What do you know about sustainability?

6- What do you think is a sustainable building?

7- What do you think sustainable architecture should be like in your community?

8- How would you define a good place to live and work?

9- How would you define a good community space?

10- How would you define a good town?

11- What do you expect to do in a participatory design workshop?

12- Do you think participatory processes are useful? How do you think this will benefit you?

\section{Part I: Property and land}

1- How easy is to find buy property in the area?

2- How easy is to find agricultural land in the area?

\section{Appendix 3 Lits of Interviews}

\section{List of Interviews}

Interview 1a: El Churcal Community Leader (Roberto)

Interview 2a El Churcal Flood Barriers (Cavakayu)

Interview 2b El Churcal Flood Barriers (Cavakayu)

Interview za El Churcal Community Discussion

Interview 1 b El Churcal Community Leader (Roberto)

Interview zb El Churcal Community Discussion

Interview зс El Churcal Community Discussion

Interview 3d El Churcal Community Discussion

Interview 4 La Quiaca, El Marques, Clara

Interview 5 El Moreno Community Leader

Interview 6 Natalia Human Rights Social Worker

Interview 7 Red Puna envoy to the United Nations

Interview 8a Rinconada Community Leader, Gerardo

Interview 8b Rinconada Community Leader, Gerardo

Interview 8c Rinconada Secretary of Public Works

Interview 8d Rinconada Community Discussion Communications

Interview 8e Rinconada Community Discussion Walkabout

Interview $8 f$ Rinconada Community Discussion Water project

Interview 9 Suripujio Community leader, Amalia 
i There are more than 30 different ethnic groups in Argentina (Encuesta Complementaria de Pueblos Indígenas -ECPI for its
Spanish acronym- INDEC 2004). The Coya population is 70,505 with 53,106 living in Jujuy and Salta and speak their native language (Coya) as well as Spanish. 